\title{
The Spatial Variation Characteristics of Physical Conditions of College Students in Jiangsu Province
}

\author{
Bo Chen, Dongjin Xian*, Yuhao Gu \\ Changzhou University, Sports Institute, School of Physical Education of Changzhou University, Changzhou, China \\ Email: *DongjinX@cczu.edu.cn
}

How to cite this paper: Chen, B., Xian, D.J. and Gu, Y.H. (2017) The Spatial Variation Characteristics of Physical Conditions of College Students in Jiangsu Province. Applied Mathematics, 8, 868-877. https://doi.org/10.4236/am.2017.86068

Received: May 2, 2017

Accepted: June 26, 2017

Published: June 29, 2017

Copyright $\odot 2017$ by authors and Scientific Research Publishing Inc. This work is licensed under the Creative Commons Attribution International License (CC BY 4.0).

http://creativecommons.org/licenses/by/4.0/

\begin{abstract}
As an important component of national talent resources, the physical conditions of college students appear to be particularly important. Based on geographic information system platform of ArcGIS, this paper builds database to make a statistical analysis on the physical conditions of college students in Jiangsu province in the years of 2012 to 2016, using the analysis function and graphics. The conclusions: 1) The students' physique conditions in Jiangsu province is in an overall downward trend;2) There are differences between the male and female college students' physical changes; 3 ) In view of the college students' physical deterioration degree of agglomeration, different areas should adopt effective measures to strengthen students' physique.
\end{abstract}

\section{Keywords}

Physical Health, Physical Change Conditions, Global Autocorrelation Coefficient

\section{Introduction}

National physical fitness is an important part of a national power, the improvement and enhancement of which is the inevitable result of the national economic development. And it is also a driving force for the development of the society. Along with rapid economic development, the physique of teenagers in our country has changed a lot [1]. As an important component of national talent resources, the students' physique is particularly important. Jiangsu province has always attached great importance to students' physical fitness research work. The students' physique monitoring has been normalized and institutionalized, 
and college students' physical health test has also become the annual work of universities. Geographic information system (GIS) is the open systems of the geographical spatial information acquisition, processing, storage, and analysis, which has been widely used in environmental, planning, monitoring, health and other fields [2]. To study the changes of the physical conditions of college students in Jiangsu province in recent years, this paper carries out a research based on ArcGIS, by using samples of the students' physique health test data in the years of 2012 and 2016 in Changzhou University.

\section{Object and Methods}

\subsection{The Research Object}

The object of this study is the physical change conditions of college students in Jiangsu province, according to the students' physique health test results in Changzhou University in the years of 2012 and 2016. It stratified sample proportions randomly according to the city levels of Jiangsu province, of which the number of male samples is 3221, and female samples 3113 in the year of 2012, while the number of male samples is 3356 and female samples is 3289 in the year of 2016.

\subsection{The Building of Data Processing and GIS Database}

The national students physical health standards is reference documents formulated to implement the ideology of the health is first, promote students to actively take part in physical exercise and to raise the level of physical health. The standards has been modified several times and formulated according to the whole physical health status of China youth. It comprehensively evaluates the students' physical health level from the aspects of body shape, body function and physical quality. According to the physical health test content, and compared to the national students physical health standard, we will grade individually 8 test projects, including the body shape index, body function index and physical quality indicators to get the men's and women's health status and the rate of change in the years of 2012 and 2016, by calculating the total score and standardization. Based on the China international edition digital map of 1:1,000,000, made by SinoMaps Press and the state bureau of surveying and mapping of the People's Republic of China, we build database on the operating platform of ArcGIS [3], connecting the basic data and players, with extraction of planar layer of 13 cities in Jiangsu province [4].

\subsection{The Analysis Method of Spatial Autocorrelation}

Spatial autocorrelation is the interrelated analysis method of geographic things:

It is used to test a certain geography elements if the same attribute values associated with adjacent area. There are three kinds of specific analysis of the results: positive correlation, space independence and space negative correlation. In normal conditions, spatial autocorrelation coefficient is divided into two broad categories: Global autocorrelation coefficient and local autocorrelation coefficient. 


\subsubsection{Global Autocorrelation Coefficient}

Global autocorrelation coefficient shows the spatial characteristics of the object property values in the whole area. In this paper, Moran's $I[5]$ is the research object, and the index is defined by the following formula:

$$
I=\frac{n \sum_{i}^{n} \sum_{j=1}^{n} W_{i j}\left(x_{i}-\bar{x}\right)\left(x_{j}-\bar{x}\right)}{S_{0} \sum_{j}^{n}\left(x_{i}-\bar{x}\right)^{2}}
$$

Of which, $S_{0}=\sum_{i} \sum_{j} W_{i j}$

Of which, $i \neq j, n$ is the total number of units involved in the analysis of the space, and also the total number observed variables. $X_{i}$ and $x_{j}$ respectively express the observed value of a property $x$ on the unit $i$ and $j . W_{i j}$ is the space weight, determined by the matrix of a space, and it shows the spatial position relations between unit $i$ and $j$. If unit $i$ and $j$ are adjacent in space, we stipulate $W_{i j}=1$; on the contrary, if unit $i$ and $j$ are not adjacent in space, we stipulate $W_{i j}=0$.

Moran's I obeys the progressive normal distribution.

It is expected as: $E(I)=-1 /(n-1)$

Variance is: $\operatorname{Var}(I)=\frac{n^{2} S_{1}-n^{2} S_{2}+3\left(S_{0}\right)^{2}}{\left(S_{0}\right)^{2}\left(n^{2}-1\right)}$

Of which: $S_{1}=\frac{1}{2} \sum_{i=1}^{n} \sum_{j=1}^{n}\left(W_{i j}+W_{j i}\right)^{2}$

$$
S_{2}=\sum_{i=1}^{n}\left(\sum_{j=1}^{n} W_{i j}+\sum_{j=1}^{n} W_{i j}\right)^{2}
$$

The data range of Moran's $I$ is between -1 and +1 . The greater the absolute value of Moran's $I$ is, the spatial autocorrelation in the research area is stronger. For index Moran, it usually tests $n$ in all areas if there is spatial autocorrelation, using the standardized statistics. Among which:

$$
Z(I)=\frac{|I-E(I)|}{\sqrt{\operatorname{Var}(I)}}
$$

When $Z(I)$ is larger than 1.65 , it shows that there is positive space correlation, when $Z(I)$ is less than 1.65 , there is negative space correlation, and when $Z(I)=0$, there is no space correlation. The observed values distribute independently and randomly.

\subsubsection{The Local Spatial Autocorrelation Coefficient}

In the process of overall autocorrelation research, there is always very different local autocorrelation in the entire study area. And this situation cannot be described by overall authocorrelation. In this situation, the academic field introduced analysis of local autocorrelation. The index is defined as:

$$
G_{i}=\frac{\sum_{i} w_{i j} x_{j}}{\sum_{j} x_{j}}
$$


The standardized test values: $Z\left(G_{i}\right)=\frac{G_{i}-E\left(G_{i}\right)}{\sqrt{\operatorname{Var}\left(G_{i}\right)}}$

When $Z\left(G_{i}\right)$ is larger than 1.65 , it shows that there is positive space correlation, when $Z\left(G_{i}\right)$ is less than 1.65 , there is negative space correlation, and when $Z\left(G_{i}\right)=$ 0 , there is no space correlation. The observed values distribute independently and randomly.

\subsubsection{The Spatial Weight Matrix}

The spatial weight matrix uses spatial weight matrix to determine the number $W_{i j}$ in above formula. The matrix is to show the space relations of samples analysis in the area. According to different standards, wan define different spatial relations and get a different $W$ space relation matrix. The pattern of manifestation of $W$ space relation matrix is:

$$
W=\left[\begin{array}{cccc}
w_{11} & w_{12} & \cdots & w_{1 n} \\
w_{21} & w_{22} & \cdots & w_{2 n} \\
\vdots & \vdots & \ddots & \vdots \\
w_{n 1} & w_{n 2} & \cdots & w_{4 n}
\end{array}\right]
$$

In the above matrices, $w_{i j}$ shows the space relations of unit $i$ and $j$. Concrete numerical value requires a certain standard to determine. Typically the involved standards include binary adjacency matrix, weighted centroid distance matrix and the recent distance weighting matrix. This paper takes binary adjacency matrix as standards. If space unit $i$ and unit $j$ have the common boundary, they will be defined as not adjacent, and $W=1$, and if they have no common boundary, $W=0$.

\section{Result}

\subsection{The Total Score Change Characteristics of College Students in All Cities}

By grading related test items in physical fitness test over the years, and calculating the total score and standardizing, then we get the male's and female's health status and the rate of change of 13 cities in the years of 2012 and 2016. In ArcGIS, we do visual expression. Figure 1 and Figure 2 show the physical health changes of male and female college students in all cities of Jiangsu province in the years 2012-2016.

From Figure 1, we can know that in the recent 5 years, the physical health test scores of male college students in Jiangsu province except Xuzhou city fall, which is not optimistic. The physical health of college male students in Nantong city degrades the most, and the change rate is little in Suzhou, Zhenjiang and Suqian. The physical health changes of male college students in most cities are similar.

From Figure 2, we can know in recent 5 years, the physical health test scores of female college students in Jiangsu province also fall, and the overall rate of change are similar to those of male college students. The most serious city where the female college students' physical health degrades is Zhenjiang, while the female 


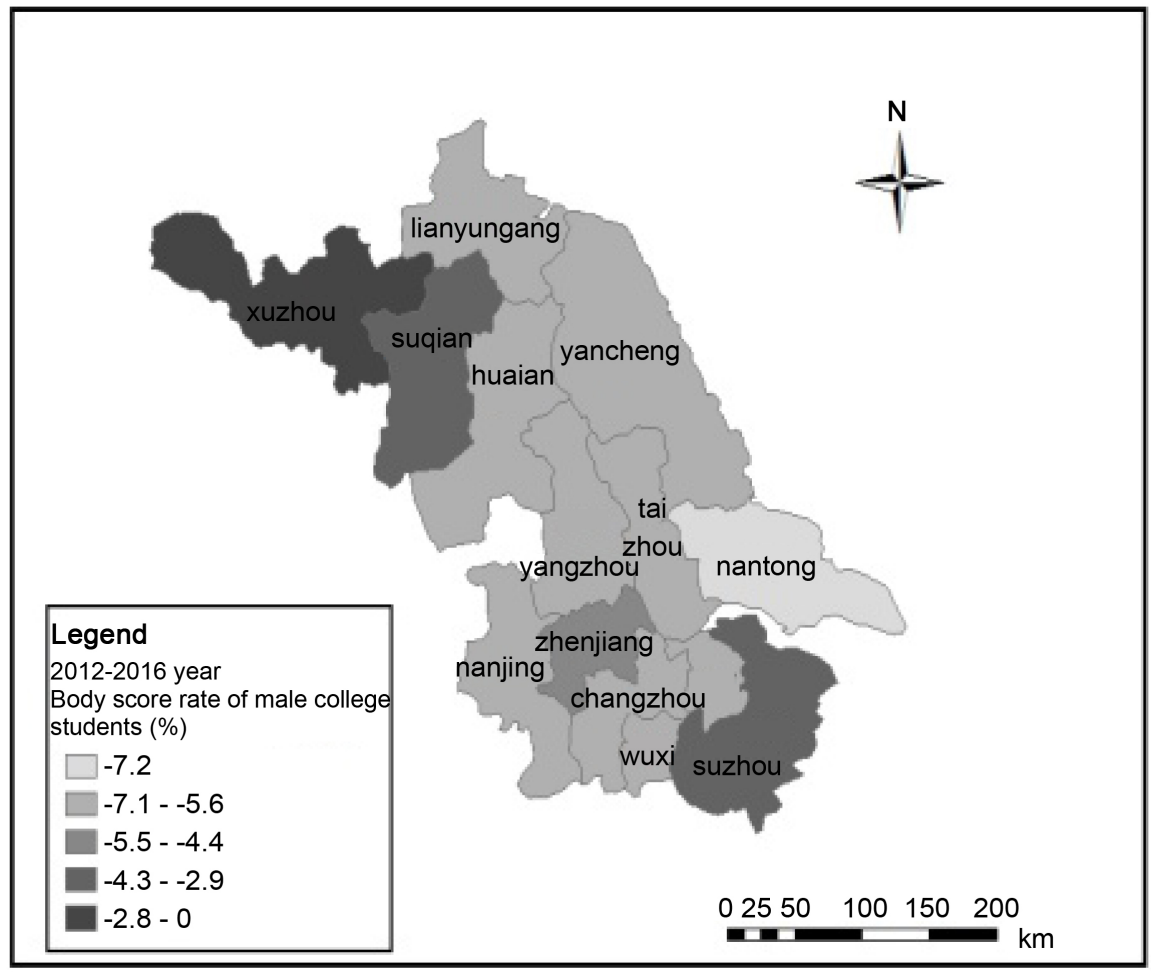

Figure 1. The score changes rate of male college students' physique in all cities of Jiangsu province in the years 2012 to 2016.

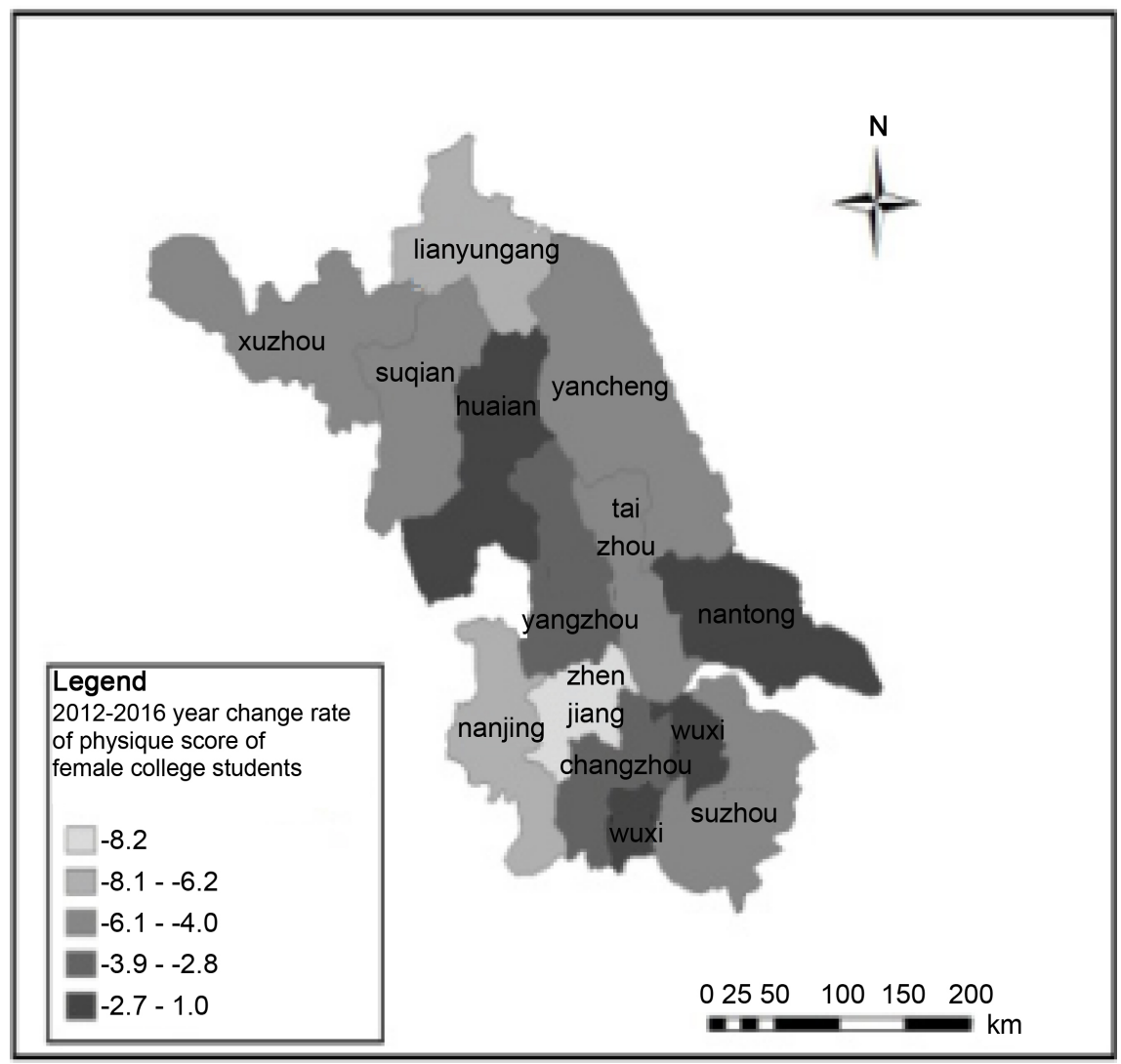

Figure 2. The score changes rate of female college students' physique in all cities of Jiangsu province in the years 2012 to 2016. 
college students' physical health changes the least, and female college students' physical health degrade rates of Nanjing and Lianyungang are similar, and that of Nantong and Wuxi are similar.

In terms of regional distribution, the similarity of male college students' physical conditions changes in entire province. The space is in consistent state in north and south. The changes' differences in all cities in the northern Jiangsu area (Xuzhou, Lianyungang, Huaian, Suqian and Yancheng) are big, while the change differences in the central section area of Jiangsu Province (Yangzhou, Taihou and Nantong) are little and that in southern regions of Jiangsu (Nanjing, Zhenjiang, Changzhou, Wuxi and Suzhou) are similar. The cities where change differences are little are distributed in the northwest-southeast direction. The space distribution rules of female college students' physical health changes are not clear. It is noteworthy that there is significant difference between the male and female college students' physical health changes.

\subsection{The Whole Space Characteristics}

We analyze the total score change situation of college students' physiques in overall space in 13 cities in Jiangsu province, and process the male and female college students' physical change rate, based on binary relating right weight matrix. In ArcCatalog10, we calculate overall situation Moran's index I and standardized result $Z(I)$. Related results are shown in Table 1 .

From Table 1, the fact that the male college students' physique change standardized result $Z(I)>1.65$ in Jiangsu province in the years 2012 to 2016 shows there is positive spatial correlation in the male college students' physique change situations, and there is spatial agglomeration in physical change differences. The places where physical changes are similar are adjacent in geographical range. While the fact that the female college students' physique change standardized result $Z(I)>1.65$ in 13 cities in Jiangsu province show that the female college students' physique change situations have the same trend in spatial area in the years of 2012 to 2016 with male students, and there is positive spatial correlation. But viewing the male and female college students of $Z(I)$ value, the dispersity degree of female college students' physical changes in spatial agglomeration situation is higher, not as clear as male college students' physical changes in spatial agglomeration situation.

\subsection{Local Space Characteristics}

According to the male and female college students' physical change data in the years of 2012 to 2016, we get the spatial distribution trend of physical change

Table 1. Moran's I and $Z(I)$.

\begin{tabular}{ccc}
\hline Local Variable & Moran's & $Z(I)$ \\
\hline $\begin{array}{c}\text { Male college students' physique change rate } \\
\begin{array}{c}\text { Female college students' } \\
\text { physique change rate }\end{array}\end{array}$ & 0.512 & 2.81 \\
\hline
\end{tabular}


situation in local areas. We draw statistical map in ArcGIS, according to the calculated local statistical value $G_{i}$ and standardized value $Z\left(G_{i}\right)$, as shown in Figure 3 and Figure 4.

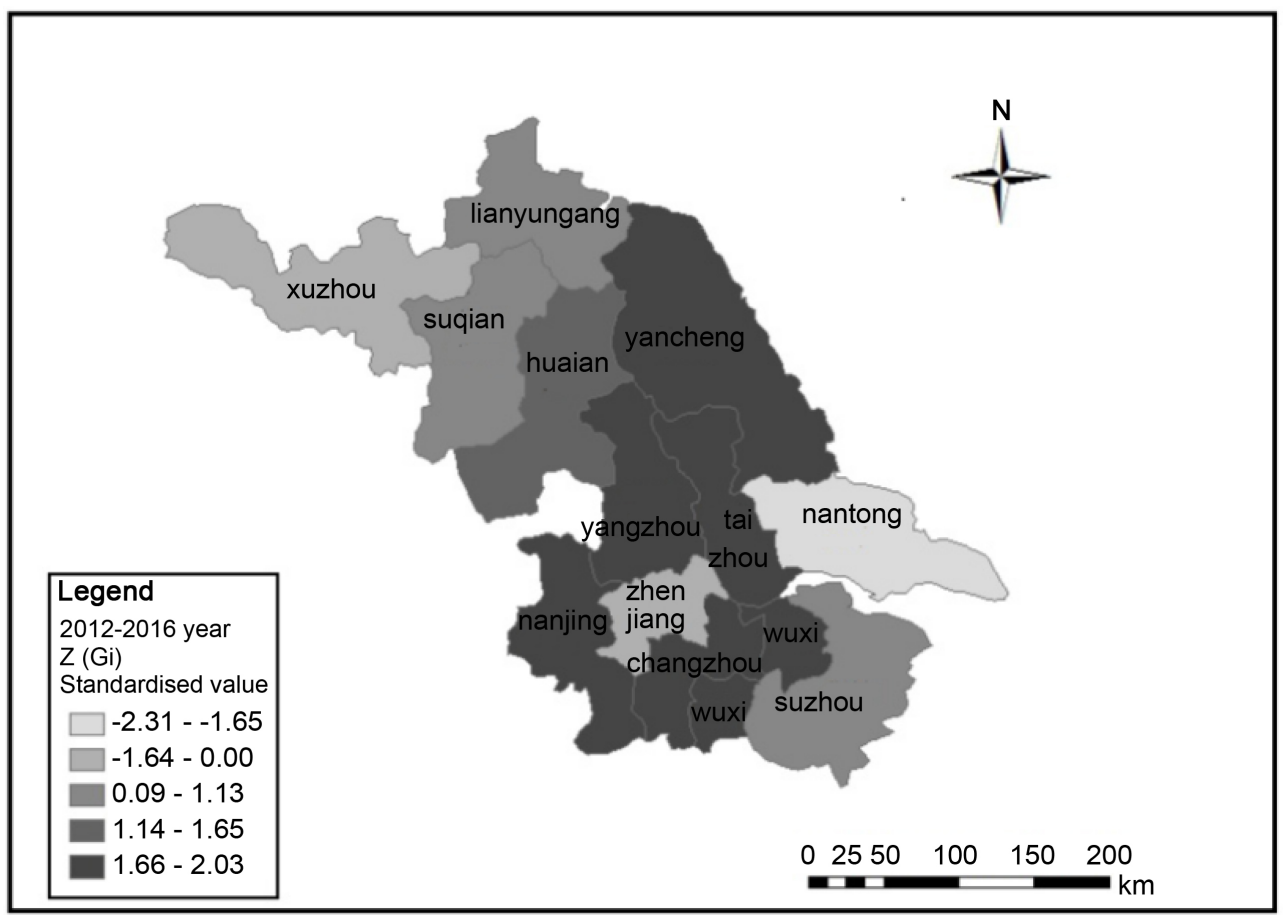

Figure 3. The male college students' physical change spatial autocorrelation analysis $Z(I)$ value in Jiangsu province in the years 2012 to 2016.

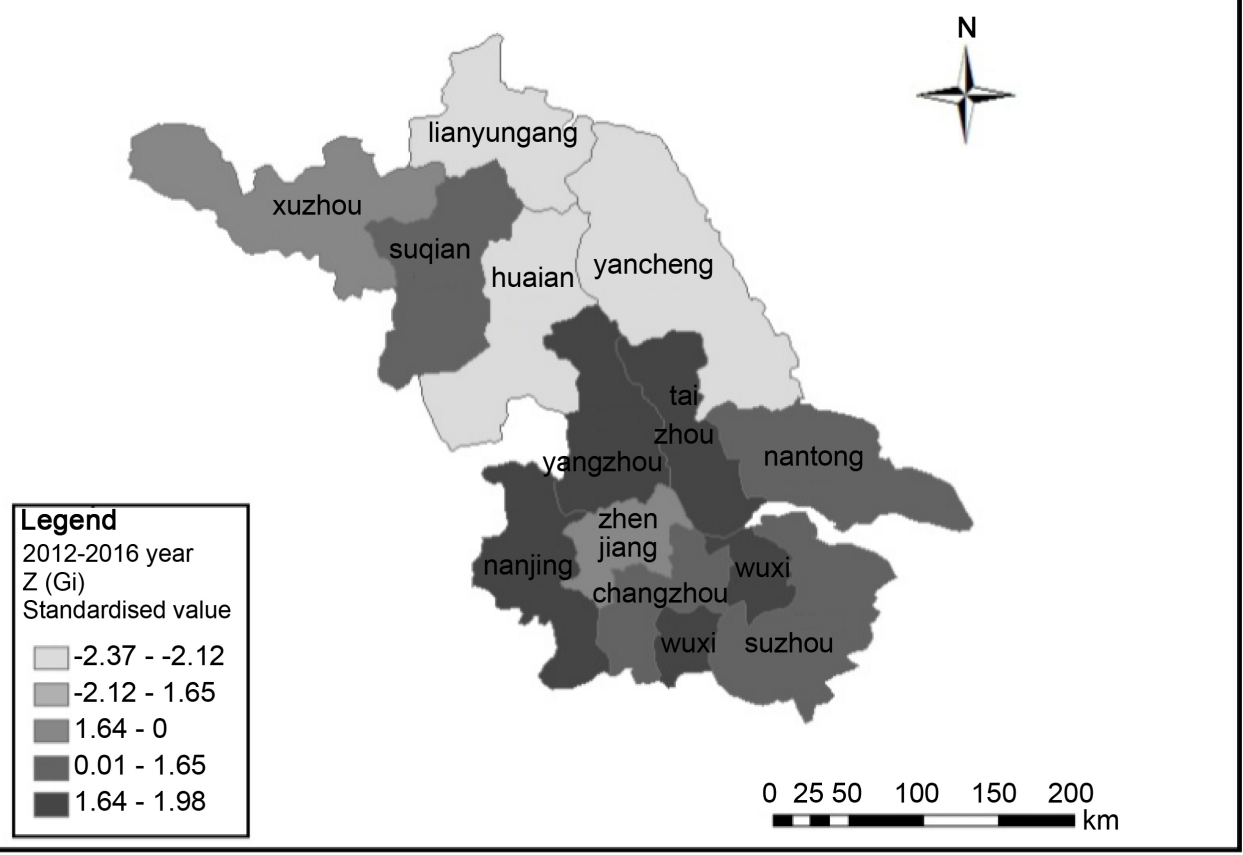

Figure 4. The female college students' physical change spatial autocorrelation analysis $Z(I)$ value in Jiangsu province in the years 2012 to 2016. 
Figure 3 shows that the male college students' physical health change situation $Z\left(G_{i}\right)>1.65$ in Nanjing, Changzhou, Wuxi, Taizhou, Yangzhou and Yancheng appears as spatial positive correlation, which states that there is high observation agglomeration in male college students' physical changes in 6 cities and physical changes of students converge greatly. In Nantong and Zhenjiang cities $Z\left(G_{i}\right)<-1.65$, which shows that there is spatial negative correlation in two areas, and it forms low growth space. The students' physical change trend convergence becomes little. The male college students' physical change in Xuzhou city $Z\left(G_{i}\right)=0$ shows that observations are scattered dispersedly, not aggregate with the surrounding area.

Figure 4 shows that the female college students' physical health change situation $Z\left(G_{i}\right)>1.65$ in Nanjing, Changzhou, Wuxi, Taizhou and Yangzhou indicates there is high observation agglomeration in female college students' physical changes in 5 cities and the change situation convergence trend become similar. $Z\left(G_{i}\right)<-1.65$ in Lianyungang, Huaian and Yancehng, which shows female college students' physical change has low concentration.

\section{Discussion}

We draw the conclusion of college students' physique fall in the time dimension, by studying the college students' physical health situation in Jiangsu province in the years of 2012 to 2016. Besides, we know there is agglomeration effect in the change situation through Moran's I, and the college students' physical fall is the trend in the whole province. And the downtrend has no difference in different areas. According to former study results [7] [8], there is no spatial correlation between the excellent national constitutional condition in Jiangsu province and economic development (Per Capita GDP). The economic development has no direct influence on the improvement of physical health.

In space perspective, on the basis of college students' physique fall in the whole province, the students' physique difference has different features in different areas: The male college students' physique deterioration rate shows an increasing trend in Nanjing, Changzhou, Wuxi, Taizhou, Yangzhou and Yancheng. This area distributes in the north and south direction, and they connect in space. There is negative trend in Nantong and Zhenjiang, the physique deterioration has low growth rate. The female college students' physique deterioration rate increases in synchronization in Nanjing, Changzhou, Wuxi, Taizhou and Yangzhou, while decrease in synchronization in Lianyungang, Huaian and Yancheng.

There is no direct relation between male and female college students' physical change trend in the same city. But considering from a whole unit, the male and female college students' physique deterioration rate increases in Nanjing, Taizhou, Yangzhou, Changzhou and Wuxi, from which cities in the southern Jiangsu are in the majority and there is no cities in northern Jiangsu, which indicates that the southern part in Jiangsu province is the more prominent area, where college students' physique deteriorates in Jiangsu province, then is the middle area of Jiangsu Province, and finally is the northern area of Jiangsu province. 
College students' physical health decline is the problem across the country today. From the actual situation of Jiangsu province, it connects both the objective factors of economic development and human factors in the process of social transformation. In the process of economic development, human production and life style have changed fundamentally. In more economically developed area, the intelligence intensive industry agglomerate, and mental labor is predominant in the production process, so teenagers don't need to do manual labor and the number of exercising reduces gradually. The level of economic development in Jiangsu province decreases from south to north, which is in accordance with the physical conditions of students. From the point of view of the way of life, the intelligence and information life are increasingly obvious characteristics at present, college students' life and study ways change quickly. Life becomes more convenient, so the movement time in students' life reduce greatly.

In view of the male and female college students' physical change conditions in different cities, we should improve the students' fitness consciousness. Physical conditions of college students in the areas of southern decline significantly. Society should invest more facilities, and should pay attention to youth when creating the national fitness atmosphere, especially the college students' and high school graduates' participation. Colleges should pay attention to students' physical exercise, and actively advocate "three walking" activity. College students in the southern area of Jiangsu province should attaches great importance to their health, and participate in physical exercises to improve their physical quality. The middle area of Jiangsu province, especially Yangzhou and Taizhou, should pay attention to the college students' change trend and stop physical declination. The college students' physique deterioration has low growth trend in the northern area of Jiangsu province, so they should also pay attention to students' physiques.

\section{Conclusion}

By analyzing the college students' physical health test data in Jiangsu province in the years 2012 to 2016, we can draw conclusions: 1) College students' physical deterioration is in the overall trend, and the spatial agglomeration degree of the trend is high. The male's agglomeration degree trend is clearer than female's; 2) Municipal college students physical changes vary in different cities, and Nanjing, Taizhou, Yangzhou, Changzhou and Wuxi are the more prominent areas where college students' physique deteriorate in Jiangsu province; 3) Different areas should adopt effective measures to strengthen students' physique according to college students' physical deterioration degree.

\section{References}

[1] Li, S., Tang, Q., Sheng, L. and Huang, H.M. (2012) The Distribution Trend of Adult Obesity and Hypertension in Jiangsu Province. China Sport Science and Technology, 48, 127-132.

[2] Tang, G.A. and Yang, X. (2006) ArcGIS Geographic Information System Spatial 
Analysis Experiment Tutorial. Science Press, Beijing.

[3] The State Bureau of Surveying and Mapping of the People's Republic of China (1996) 1:1,000,000 China Digital Map (DMDC), International Edition. SinoMaps Press.

[4] Qian, W.L. and Pan, X.G. (2010) Build of Students' Physique Evaluation System Based on GIS. Journal of Huzhou Teachers College, 1, 56-59.

[5] ESRI. (1998) Getting to Know ArcGIS: The Geographic Information System (GIS) for Everyone. Environmental Systems Research, Inc., Redlands, CA, USA.

[6] Walter, T. (1996) The Spatial Antocorrelation Coefficient Moran's I under Heteroscedasticit. Statistics in Medicine, 15, 887-892.

https://doi.org/10.1002/(SICI)1097-0258(19960415)15:7/9<887::AID-SIM257>3.0.C O;2-E

[7] Li, S. and Sheng, L. (2007) The New Attempt of National Health Data by Using GIS Technology. Journal of Beijing University of Physical Education, 12, 1639-1641.

[8] Li, S., Huang, H.M. and Xu, H. (2008) The Application of Spatial Autocorrelation of the National Constitution in Jiangsu Province. Sports and Science, 1, 76-79.

Submit or recommend next manuscript to SCIRP and we will provide best service for you:

Accepting pre-submission inquiries through Email, Facebook, LinkedIn, Twitter, etc. A wide selection of journals (inclusive of 9 subjects, more than 200 journals)

Providing 24-hour high-quality service

User-friendly online submission system

Fair and swift peer-review system

Efficient typesetting and proofreading procedure

Display of the result of downloads and visits, as well as the number of cited articles

Maximum dissemination of your research work

Submit your manuscript at: http://papersubmission.scirp.org/

Or contact am@scirp.org 